\title{
A Dialectic of Race Discourses: The Presence/Absence of Mixed Race at the State, Institution, and Civil Society and Voluntary and Community Sector Levels in the United Kingdom
}

\author{
Chinelo L. Njaka
}

check for updates

Citation: Njaka, Chinelo L. 2022. A Dialectic of Race Discourses: The Presence/Absence of Mixed Race at the State, Institution, and Civil Society and Voluntary and Community Sector Levels in the United Kingdom. Social Sciences 11: 86. https://doi.org/10.3390/ socsci11020086

Academic Editors: David L. Brunsma and Jennifer Sims

Received: 2 October 2021

Accepted: 15 February 2022

Published: 21 February 2022

Publisher's Note: MDPI stays neutral with regard to jurisdictional claims in published maps and institutional affiliations.

Copyright: (C) 2022 by the author. Licensee MDPI, Basel, Switzerland. This article is an open access article distributed under the terms and conditions of the Creative Commons Attribution (CC BY) license (https:// creativecommons.org/licenses/by/ $4.0 /)$.
Independent Researcher, London SE15, UK; chinelo.njaka@gmail.com

\begin{abstract}
For the twenty years that mixed race has been on the United Kingdom (UK) censuses, the main story of mixed race in the UK remains one notable for its nominal presence and widespread absence in national discourses on race and ethnicity, racialisation, and racisms. The article explores reasons for this through connecting the continued presence/absence of mixed race in public discursive spheres to the role that White supremacy continues to play at systemic, structural, and institutional levels within UK society. As technologies of White supremacy, the article argues that continued marginalisation of mixed race has a direct connection to systemic, structural, and institutional aspects of race, racialisation, and racisms. Using three case studies, the article will use race-critical analyses to examine the ways that mixed race is present and-more often-absent at three societal levels: the state, institution, and civil society and voluntary and community sector. The paper will conclude by exploring key broad consequences for the persistent and common presence/absence of mixed race within race and racisms discourses as a technology of political power. Working in tandem, the paper exposes that presence/absence continues to affect mixed race people-and all racialised people-living in and under White supremacy.
\end{abstract}

Keywords: mixed race; race; racisms; racism; racialisation; United Kingdom; white supremacy; BAME; discourse analysis; race-critical

\section{Introduction}

For the last two decades, mixed race has been on the United Kingdom (UK) censuses, and thus officially added to the racialised groupings recognised in nearly all UK institutions, organisations, and for individual identity preferences. Nevertheless, the main story of mixed race in the UK remains one notable for its nominal presence and widespread absence in public discourses on race and ethnicity, racialisation, and racisms. In this article, I explore the reasons for this through connecting the continued presence/absence of mixed race in public discursive spheres to the role that White supremacy continues to play at state, institutional, and civil society and voluntary and community sector (VCS) levels within UK society today.

In the production of knowledge, absences matter. This is particularly true when absences remain unacknowledged or are otherwise deemed unimportant. For mixed race, its (dis)missing within wider discourses around race and racialisation has grave implications for our understanding of racial dynamics in the twenty-first century. Most generally, missing information remains a gap, or is filled with assumptions that may or may not be representative or relevant to mixed race groups. A result of that, in line with the reflections of Byrne (2005) around absences, is that there may be (limited) quantitative knowledge about numbers and statistics about mixed race, but absences lead to limited qualitative knowledge about the views and lived experiences of being mixed race.

In this article, I seek to expand our qualitative knowledge by examining the absences within the presence of mixed race in racial discourses. I argue that the presence/absence of 
mixed race reveals continued marginalisation and subsumption as part of the work and result of White supremacy. Through exposing the dynamics of presence/absence, we can better understand how racialised oppression continues to be reproduced even as societies struggle for racial equality.

\section{Race as a Technology of White Supremacy}

White supremacy can be conceived of as a socio-cultural, political, and economic system where power and resources are controlled by a White racialised majority (Christian 2002; Macfarlane 2021). Historically and contemporarily, this system leads to the widespread dynamics of implicit and explicit notions of White superiority and dominance verses "non-White" ${ }^{1}$ inferiority and subordinance enacted and embedded across all areas of society from the macro- to micro-levels (Macfarlane 2021). For the UK, White supremacy was the justification for over five hundred years of imperial, colonial, and enslavement projects; the legacies of which are still apparent in the present day as evidenced by persistent racialised disparities and disadvantage (Christian 2002). Further, the rise of racialised Islamophobia and anti-immigrant sentiments over the last two decades, racialised concerns about globalisation and multiculturalism, nationalist populism, and imperial nationalism ${ }^{2}$ also can be linked to White supremacy (Bhambra 2017; Flemmen and Savage 2017).

It may seem, therefore, an obvious link to state that race itself (e.g., categories, logic, and $\operatorname{racism}(\mathrm{s})$ ) is a by-product of White supremacy. However, this paper argues from a more nuanced perspective as it shines light on the how — the mechanics—of White supremacy. It is a largely uncontroversial understanding in current mainstream race scholarship that race is not based on anything biological, but rather is a social construction. Though this is also widely accepted in extra-academic - or everyday-spaces, from international institutions to community groups, the discourses and operationalisations of the social construction of race quickly reveal faults. In previous research, I find that representatives from UK-based mixed race civil society frequently assert that race is a social construction, but when asked how they understand race and mixed race for the purposes of their work, responses show various levels of slippage ${ }^{3}$ into biological race paradigms (Sims and Njaka 2020; see also Bullock 2010). This aligns with other explorations into the efficacy of "social construction" to explain race for everyday contexts (Essed 1991; Glasgow 2009).

Race scholarship has also entered the debate of the efficacy of treating race merely as a social construction. Ian Hacking raises the pivotal titular question, The Social Construction of What? (1999), and therein lies the conundrum-for race, the answers to this question circle around biology, but do not move scholars much away from it (Hacking 1999; Hesse 2013; Lentin 2020). Conversely, asserting that "race is a social construction of biological misconceptions of race" - effectively applying a social label to biological paradigmsfunctions to relegitimise race and reify it through perpetuating the logics, inequalities, and racisms that biological race created in the first place (Fields and Fields 2014; Hesse 2013; Lentin 2020). Leaving race as just a social construction has limited impact on the dismantling of race, racisms, and racialisations; and raises more questions than it answers.

In Why Race Still Matters, Lentin (2020) develops the social framing of race as a way to move beyond the "race as social construction" tautology and further examine implications of its socio-political development. She posits race and racism(s) as separate but linked political projects that act as technologies of White supremacy to construct and maintain notions of human difference (Lentin 2020; Njaka 2021). I propose that racialisation-as distinct from race and racisms-is an additionally linked political project that also works within this framework of White supremacy, as it is the location for the dynamic shifting and contesting of meanings for race and racisms within societies (Njaka 2021). Through this reimagination of race as a power and technology of White supremacy, we can liberate ourselves from the superficial circuity of "social construction" and better understand the logics, functions, and repercussions of race in the social world.

Throughout this article, my aim is to develop this framework of race as a technology of political power. I achieve this through locating the research within the context of the UK 
and applying the framework to the constructions and operationalisations of mixed race within the larger context of constructed race and ethnicity within the UK.

\section{Race and Mixed Race in the UK}

Race, racisms, and racialisation were born out of imperialism, colonialism, and enslavement (Byrne et al. 2020; Lentin 2020; Sims and Njaka 2020). In part, they were used as rationales for the subjugation of fellow human beings through these projects of White supremacy. This setting up of binaries of us versus them (civilised versus savage, good versus evil, sophisticated versus primitive, and White versus Black, etc.) to condone domination reveals a tacit logic of race. Race shapes racialisations as necessarily discrete and unequal in categorisation, which in turn justifies racisms against those with less power.

The logics and categorisations of race, racisms, and racialisation create the foundations of the maintenance of the socio-political power of White supremacy. Race functions whether it is explicitly named and acknowledged or remains implicitly operational, belying colourblind discourses and policies. Forms of racisms are ubiquitous in every nation in the world, shaped by specific regional, cultural, and socio-historical contexts. Racialisation occurs at all levels of society, creating significance and judgement for human differences (Office of the United Nations High Commissioner for Human Rights (OHCHR) and United Nations Educational, Scientific, and Cultural Organization (UNESCO) 2003). Race, racisms, and racialisation form the framework of White supremacy through identifying and creating artificial divisions that determine the social positioning of people within a system of racialised hierarchy.

Within the UK, the state recognises race, which is a departure from most other European nations that do not in order to distance themselves from appearing to sanction the historical biological underpinnings of race in the aftermath of the Holocaust (Byrne et al. 2020; Goldberg 2006; Lentin 2008, 2020). For similar reasons, the UK officially uses the term "ethnicity" instead of "race" to describe ethno-racialised groups, though the logics and applications are parallel to race (Sims and Njaka 2020). Moreover, "race" is still used in some legislations, such as the Equality Act 2010, and remains commonly used in "unofficial" non-state and everyday contexts throughout the UK.

In 1991, England, Wales, and Scotland began counting ethnicity explicitly on the decennial census and a "Mixed" option was added in 2001. For Northern Ireland, both an ethnicity question with a "Mixed" option was added in 2001. The 2021 census specimen for the ethnicity question in England is shown in Figure 1. For England and Wales ${ }^{4}$, the most recent census in 2021 lists five main ethnicity groups in a column from top to bottom: White, Mixed or Multiple ethnic groups, Asian or Asian British, Black, Black British, Caribbean or African, and Other ethnic group (GOV.UK 2021a). Within these groups are constructed the (sub-)ethnic groups with select mostly ethno-national categories (e.g., British, English, Irish, and Indian), though some are broader and cover cultural groups (i.e., Gypsy or Irish Traveller and Arab), geopolitical regions (i.e., British ${ }^{5}$ and Caribbean), or continents (i.e., African). Additionally, there is an option within each main ethnicity group to write in any other background. Particular to the Mixed or Multiple ethnicity group, the (sub-)ethnic groups are listed as White and Black Caribbean, White and Black African, White and Asian, and any other Mixed or Multiple ethnic background, which reflect the options from the five main ethnicity group categories. 


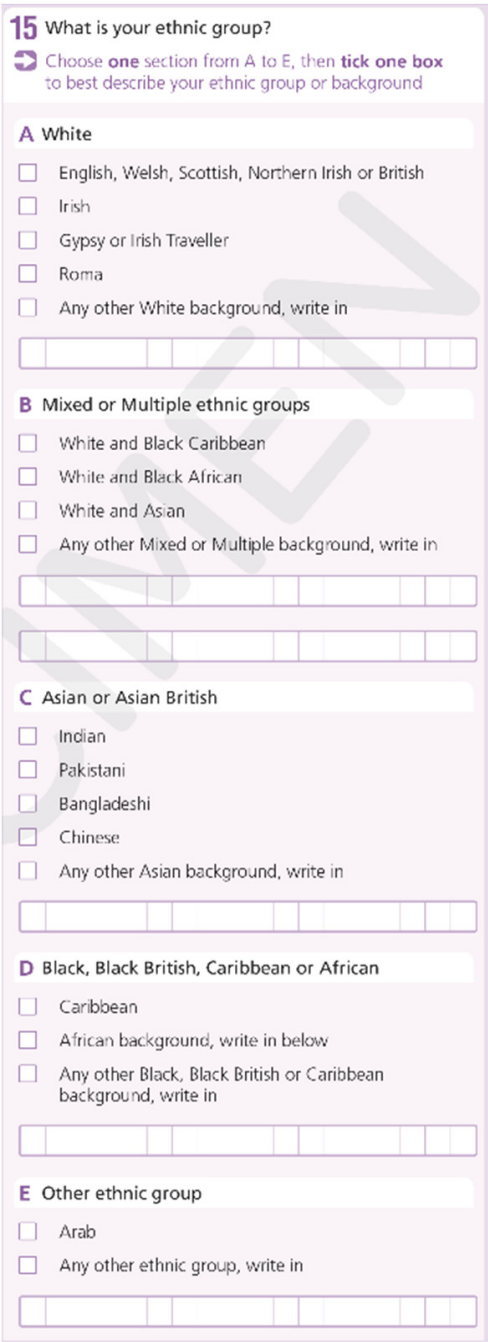

Figure 1. 2021 Census specimen of the ethnicity question for England Source: Office for National Statistics. Licenced under the Open Government Licence v.3.0.

These categories are the officially recommended ethnicity groups by the UK government, and guide racial categorisation and ethic data collection throughout most sectors of society, including local authority, health and social care, and employment.

The structure of the ethnicity census question reveals the racial hierarchy within the UK. Through examination, it also reflects some of the tension embedded within it as it negotiates race, mixed race, and White supremacy. Within the columnal question, White appears at the top, followed by Mixed or Multiple ethnicity (with White and a minoritised ethnicity as given options). The next one down is Asian or Asian British, and last before the Other category is Black, Black British, Caribbean, or African. The ordering places stereotypically lighter-complexioned groups at the top and darker-complexioned groups at the bottom, or, in other words, along a continuum from proximity to Whiteness (Ahmed 2007; Dyer 2017; Sims and Njaka 2020).

Mixed race does not fit with ease within the structures of discrete ethnic categorisation. In the UK, the category to capture mixed race was added alongside the existing categories rather than developing an alternative method, e.g., allowing free multiple ethnicity selections. Although labelled as "multiple", the provided options within the Mixed or Multiple ethnicity group are limited to only two of the larger categories, and one of the ethnic groups must be White (unless selecting Other to write-in ethnicities). Despite this and the consequent proximity to Whiteness, Mixed or Multiple ethnicities are minoritised groups - their Whiteness disappears, and groups are often compared to or amalgamated 
with their "non-White" ethnic counterparts. Other Mixed or Multiple backgrounds that may be more diverse than the given options (including ethnicities not officially recognised) are more difficult to capture and largely ignored (Sims and Njaka 2020).

This presence/absence of mixed race is but one aspect of how White supremacy functions in the UK and other comparable White hegemonic societies. Even though currently the Mixed or Multiple ethnicity group is still numerically smaller than the other main ethnicity groups, mixed race is present in that it is an officially recognised ethnicity group. Since 2001, the Mixed or Multiple ethnicity group remains one of the fastest growing ethnicity groups and is significantly shaping the racialised landscape of the UK (Sims and Njaka 2020). However, within this racial structure, the almost exclusive focus on White, Asian, and Black categories functions to hide Mixed or Multiple groups, rendering them nearly invisible.

The presence/absence of mixed race is conspicuous and warrants investigation. Mixed race remains under-researched and under-acknowledged across UK sectors, from the state and its institutions through to local authorities, civil society, and the VCS. I argue that the continued marginalisation of mixed race is part of the broader technologies of White supremacy, and that this marginalisation has a direct connection to systemic, structural, and institutional aspects of race, racialisation, and racisms.

\section{Methodology and Methods}

Using three case studies, I use race-critical ${ }^{6}$ analyses to examine the ways that mixed race is present and-more often-absent in discourses of race, racialisation, and racisms. Using critical discourse analysis (CDA), I explore how mixed race is acknowledged and constructed by the state, institutions, and organisational levels using one case study for each society level. Discourse is particularly appropriate for this study because the focus of my research is not only about the text itself, but the interaction between message, messenger, and audience (Donoghue and Kuisma 2021). First, I conducted a content analysis for each case in order to identify and code key themes and words used around mixed race and race. Second, guided by the identified themes and words, I used CDA to highlight messaging and meaning, which reveals the presence and absence of acknowledgement and engagement with mixed race in the UK.

The case studies at the state and institutional levels use reports as data sources, which will be introduced in more detail for each case below. For the organisational case study, the two main data sources are from a public meeting and a published statement. The public meeting was organised by a community group based in southeast London, as part of a larger initiative by the local council and VCS support services. Founded in 2020 as a response to Black Lives Matter protests, the aims of the community group are to support local VCS organisations that are led by racialised minorities and provide services for racialised minority communities. Though I am an academic researcher, I am also an active member of the community group and lead a non-profit organisation that focuses on systemic racism and human rights for minoritised communities. My positionality is a tri-national naturalised immigrant to the UK whose reflected appraisal fits into the Black ethnicity group (Sims and Njaka 2020). With this positioning, I was able to pose questions about mixed race without being reflectively appraised as part of a Mixed or Multiple ethnic group. The anonymised data from the meeting were collected through participant-observation. Inc Arts UK, another London-based community organisation that supports diversity and inclusion in the arts, published the statement on BAME ${ }^{7}$ (Black, Asian, and Minority Ethnic) groups. The statement is the culmination of a series of events called \#BAMEOver, and is presented as a guidance for improved ways of talking about the ethnic communities in the UK. 


\section{Case Studies}

\subsection{Case One: State: Presence/Absence as Assumption}

The Commission on Race and Ethnic Disparities (CERD), chaired by Dr. Tony Sewell, CBE, was established by UK Prime Minister Boris Johnson in the summer of 2020. CERD was purportedly commissioned to investigate racial and ethnic disparities in the UK in the aftermath of the global protests against the police murder of George Floyd in Minneapolis, Minnesota, USA (Commission on Race and Ethnic Disparities (CERD) 2021). Commission on Race and Ethnic Disparities: The Report, commonly referred to as the Sewell Report, was released in March 2021 to almost universal condemnation by community groups, civil society, institutions, and even the United Nations. The 258-page report was also disavowed by several members of CERD after its publishing, as they claimed significant portions were edited or rewritten before publication (Iqbal 2021). The general findings of the report framed racism in the context of how it looked fifty years ago and found that because matters have changed or improved somewhat for racialised minorities, racism is no longer the problem that it once was. Moreover, despite the Macpherson Report from 1999 finding the opposite, the Sewell Report found there to be no evidence of systemic, structural, or institutional racism in the UK, and that much of what is assumed to be racial disparity is usually due to more "complex" issues excluding race, such as geography, economic status, culture, religion, and family structure. Examples of successes by some minoritised communities are used to support these arguments, as well as claims that the more positive narratives are underreported because they are not of much interest to the media.

Being a government-commissioned and sanctioned report, it is particularly fascinating to explore how the topics of race and ethnicity are shaped and talked about at the state level. The state plays a pivotal role in the defining and constructing of racialised categories, groupings, and communities (Anderson 1991; Omi and Winant 2015; Sims and Njaka 2020). The report uses racialised categories and guides on how-and how not-to use them. At the same time, the report makes an argument against racisms present in the UK while employing race and racialisations-the very tools that maintain racisms.

In the UK, mixed race is constructed as a minoritised group, regardless of the specific racial backgrounds found within a given group (Sims and Njaka 2020). Nevertheless, when race is being discussed, the Black, Asian, and Other ethnicity groups typically receive more specific focus than the Mixed or Multiple ethnic groups. This can be seen in the acronym BAME, which refers to the three "singular" ethnicity groups specifically (with "Minority Ethnic" closely aligning to the Other ethnicity group) but does not explicitly mention Mixed or Multiple ethnic groups. Indeed, it is not until a late footnote where the Mixed or Multiple ethnic groups are explicitly referred to as ethnic minorities, distinguished from White ethnicities (including minoritised White ethnicities) by UK government (Commission on Race and Ethnic Disparities (CERD) 2021, p. 132n). Although never a legal framework in the UK, this indicates that the state relies on paradigms of hypodescent to conceptualise Mixed or Multiple ethnic backgrounds as being distinct from all forms of Whiteness. To be "part-White" is to be "non-White."

Perhaps the most prominent recommendation from the Sewell Report is to "[d]isaggregate the term 'BAME'" and "[s]top using aggregated and unhelpful terms ... to better focus on understanding disparities and outcomes for specific ethnic groups" (Commission on Race and Ethnic Disparities (CERD) 2021, p. 14). The report also goes on to advocate for more granular data for the sixteen official UK ethnic groups and criticises the "Big 5 " level of aggregation, which collects and reports at the White, Mixed or Multiple, Asian, Black, and Other ethnicity groupings (Commission on Race and Ethnic Disparities (CERD) 2021, p. 33). Although this is a positive recommendation for improving understandings of race and racisms in the UK, it lays bare a predicament for understanding mixed race. Currently, the Mixed or Multiple ethnicity group is composed of categories that are themselves aggregated at the ethnicity group level. If when merging ethnic groups into the larger aggregations creates the problem of obscuring vastly diverse experiences and outcomes for White, Asian, Black, and Other ethnicity groups, the same is also the case when grouping, as an example, 
a Mixed Welsh and Indian person and a Mixed French and Japanese person into the same Mixed White and Asian ethnic category. The current categories available for Mixed or Multiple ethnicity groups already mask the different experiences and outcomes within this diverse group. The groups are already aggregated at their most "specific" level, and when aggregated again at the Mixed or Multiple ethnicity level, they are effectively doubly aggregated.

Despite its own recommendation, however, the Sewell Report slips quickly from using disaggregated language to aggregating ethnicity groups throughout the majority of the report. This is in line with other research that has shown that government agencies have been increasing the usage of "pan-ethnicities" aggregation since the 2011 census cycle (Aspinall 2021b). This is especially true for the Mixed or Multiple ethnicity groups and the ways that they are referred to and analysed for the purposes of the report.

White and Black African, White and Black Caribbean, White and Asian, and any other Mixed or Multiple ethnic groups are not mentioned equally within the report. Aside from inclusion in tables and figures of data, the most talked about group is White and Black Caribbean and the least talked about is the any other Mixed or Multiple ethnic groups, referred to as "Mixed Other" (e.g., Commission on Race and Ethnic Disparities (CERD) 2021, p. 56). As mentioned above, the report also makes use of aggregation and uses "Mixed ethnicity" and "Mixed ethnic group" as ethnicity group labels.

In addition to terms corresponding to Mixed or Multiple ethnic groups, the Sewell Report also makes use of higher-level aggregations that do not align with the government's own ethnic category recommendations. An example of this is when the report mentions high instances of family breakdown for "Mixed ethnicity Black children" (Commission on Race and Ethnic Disparities (CERD) 2021, p. 41). This grouping appears to combine children from the White and Black Caribbean and White and Black African ethnicities, as well as the proportion of any other Mixed or Multiple ethic groups that include other Black ethnicities. Other examples of higher-level aggregation are instances where the Mixed White and Black Caribbean group is combined with the Black Caribbean group, Mixed White and Black Africans are combined with Black Africans, and Mixed White and Asians are combined with Asians. In these instances, assumptions are made that each Mixed or Multiple ethnic group will be analogous enough to the "non-White" ethnicity group, however they are never conversely combined with White ethnicity groups for the purpose of analyses. Instead, there are cases in the report where, for example, aggregated Mixed White and Black Caribbean and Black Caribbean pupils are reported as being the least likely to receive strong General Certificates of Secondary Education (GCSEs) in direct contrast to the most likely, presented as disaggregated Indian pupils (CERD: 64). Yet another instance is the combining of any other Asian, Mixed White and Asian, and Asian Chinese into one group (Commission on Race and Ethnic Disparities (CERD) 2021, p. 64). In all of these cases, there is no justification offered as to why these ethnicities from different ethnicity groups are amalgamated, other than sample size, which does not speak to suitability for comparison. This suggests assumptions of cohesion at the expense of the real differences, conflict, and heterogeneity that have led to them being defined and conceptualised as distinct ethnicities in the UK context.

Pnina Werbner grapples with what she calls the fiction of unity for ethnic communities in the UK; a concept that Peter Aspinall also explores more recently when writing about ethnic minority communities and the COVID-19 pandemic (Aspinall 2021b; Werbner 1991). Contrasting the logic of such labels as signifying the commonalities of background, interests, social structure, values and mores, and geography, Werbner problematises the typically externally-defined labels for these imagined communities ${ }^{8}$ as romanticised and false (Werbner 1991). Those labels can at times positively stress collective consciousness and actions within the groups they are meant to describe, however Werbner argues that the "... hegemonic struggles within an ethnic community are as endemic as they are between the minority population and the wider society" (Werbner 1991, p. 78, emphasis in original). Overlooking the conflicts, struggles, and voices within groupings risks partial or false 
representation of the groups they are meant to describe, privileging one unifying narrative over the countless others within a community. Using the case study of British Pakistanis, she maps out various areas of diverse identities within the ethnic group along areas of origin and birth, language and religion, and nationality to illustrate what becomes lost under the label "Pakistani".

The concept of fictive unities can be applied to all UK ethnic groupings. If the official ethnic groups are already examples of fictive unities, then the more broadly aggregated groups are even more fictive and less unified on account of the diversity and conflicts they mask. This is especially the case when trying to isolate and understand Mixed or Multiple ethnic groups, which begin as doubly aggregated and vastly diverse because the groups themselves are identified by having more than one ethnic group affinity. The specific ways that racisms affect Mixed or Multiple ethnic groups-in particular, minoritisation and multiple racialisations - is difficult to identify and analyse when combined with groups that experience racisms differently.

Alongside the use of ethnicity group and more broad aggregation, the Sewell Report regularly mentions the Mixed White and Black Caribbean group alongside the Black Caribbean group. An example of this is when reporting on educational disparities, Black Caribbean and Mixed White and Black Caribbean groups are reported together as being mostly third-generation UK-born (Commission on Race and Ethnic Disparities (CERD) 2021, p. 68). This is in contrast to the other Mixed or Multiple ethnic groups, which are not regularly compared to their minoritised counterparts, or any other ethnic groups. Moreover, it appears that the third-generation status only applies to the Black Caribbean ancestry and not to whatever White ancestry a person may have. Although more tacit than aggregating the groups, this frequent association discursively functions in the same way, which assumes the groups are more similar and cohesive than they may be in practice. At other times, Black Caribbean and Mixed White and Black Caribbean groups are also compared alongside the White British group. These comparisons with the White British groups are used, at least in part, to disprove racisms as reasons for disproportional data. For instance, the report may point to factors such as parental education levels or family structure, neglecting to acknowledge intersectional explanations that would include racialised positioning as a significant factor in shaping social phenomena.

The explanations that the Sewell Report offers for some of the findings may begin to explain some of the racialised disparities on a broad level, however they do not fit well for the typical demographics within the Mixed or Multiple ethnicity group. The report invokes the theory of immigrant paradigm to explain education disparities. The theory posits that in contrast to "the native population", recent immigrants focus more on higher educational attainment as a means toward financial security. Similarly, "newcomer optimism" describes how recent immigrants are more optimistic about social mobility prospects (Commission on Race and Ethnic Disparities (CERD) 2021, p. 68). The report alludes to a variability among the Mixed or Multiple ethnic groups in terms of educational attainment, so it is unclear how these theories would explain those particular disparities. Moreover, when applied to Mixed or Multiple ethnicities, the "non-White" minoritised ethnicities are hyperfocused upon and the White ethnicities (whether majorised or minoritised) are assumed inconsequential or ignored. In the Sewell Report, immigration status reflects how recent the "non-White" side(s) of the family came to the UK, with no regard to where the White side(s) of the family originate(s) from, or how long ago they migrated to the UK. Despite the official categories including "British" for both Black and Asian ethnicity groups, the report primarily uses "British" in these analyses for White ethnicities, and omits it for Black, Asian, and Mixed or Multiple ethnicity groups. This further reinforces a narrative where "non-White" minoritised groups are perpetually foreign-regardless of how many generations have lived in the UK.

Similarly, selective assimilation theory is used to explain disparities between Black Caribbean and Mixed White and Black Caribbean groups associated together, Indian groups, and Pakistani groups (Commission on Race and Ethnic Disparities (CERD) 2021, p. 69). 
Here, the explanation is that Black Caribbean migrants moved into White British workingclass areas, whereas Indian migrants from higher socioeconomic classes migrated more diversely and poorer Pakistani migrants moved into areas with more "ethnic segregation". (Commission on Race and Ethnic Disparities (CERD) 2021, p. 69). Although this may partially explain the trajectory for a portion of the Mixed White and Black Caribbean group that may be working class, this explanation does not account for the Mixed White and Asian populations as the focus is only on generalisations for two specific Asian groups. As with the application of immigration paradigm theory, the "non-White" side(s) of Mixed or Multiple ethnicity groups are hyper-focused upon at the expense of the White side(s). For Mixed or Multiple ethnic groups that do not include White ethnicities at all, the discrete ways that the individual ethnic groups are generalised about make it difficult for these theories to shed light on the disparities specific to them.

The case study of the Commission on Race and Ethnic Disparities: The Report shows examples of White supremacy in action at the state level. In a report that begins by denying institutional, structural, and systemic racisms a priori, the discourses throughout the report illuminate the very racisms the report attempts to deny. This is the case for all minoritised groups in the UK. For Mixed or Multiple ethnic groups in particular, however, the presences and absences of mixed race are an interesting location to examine how race is operationalised and how racisms are perpetuated by the state.

The presence/absence of mixed race at the state level is driven by the assumptions of White supremacy. As agents of the state, CERD made discursive decisions about which ethnic groups are notable and important to include, and which ones are not. Mixed race is present in this report, but not with detail; and the narratives of each Mixed or Multiple ethnic group exploring their diversity and specific disparities are absent. Instead, there are broad assumptions and conjecture about similarities to other minoritised ethnic groups and migrant populations. The lack of acknowledgement of this problem already embedded in the categorisation of mixed race and perpetuated even more broadly reveals the oversight of interest for this significant population and the implicit assumptions of homogeneity or generalisability within the existing categories. It is surprising that given how "new" and "emergent" mixed race is said to be in the UK (Sims and Njaka 2020), there is neither acknowledgement of previous mixed-race research nor a specific recommendation for more focus and better understanding of this population. Instead of understanding the specific challenges that Mixed White and Black Caribbean, Mixed White and Black African, Mixed White and Asian, and any other Mixed or Multiple ethnic groups face, these assumptions lead to the reclassification of these diverse and dynamic ethnic groups into larger amalgamated pan-ethnic groups, based on nebulous criteria that function to create fictions of unity among the already fictive unities of the official ethnic groups in the UK.

\subsection{Case Two: Institution: Presence/Absence as Oversight}

The current COVID-19 pandemic has brought to light how racisms are linked to the health outcomes of ethnically minoritised communities in the UK, despite the denial of systemic, structural, and institutional racisms in the Sewell Report. Very early in the pandemic, it became clear that there were significant ethnic disparities in infection, hospitalisation, and mortality rates (Public Health England (PHE) 2020a, 2020b). There has been much research identifying racialised disparities in health outcomes and linking racisms to health access and care (e.g., Byrne et al. 2020; Meer et al. 2020; Platt and Warwick 2020; Proto and Quintana-Domeque 2021). However, among this research, there is an overlooking of mixed race when acknowledging health disparities. This remains true despite calls for further research that focuses on specific ethnic groups (e.g., Aldridge et al. 2020; Aspinall 2021b; Bentley 2020; Meer et al. 2020; Milner and Jumbe 2020; Platt and Warwick 2020; Treweek et al. 2020).

Public Health England (PHE) is an independent agency of the Department of Health and Social Care that provides expertise and support to government, parliamentary, health, industry, and public sectors. Early in the pandemic, PHE released two preliminary reports 
on the observed disparities of COVID-19 infection, hospitalisation, and mortality rates. The first focused more broadly on several types of disparities, and the second focused specifically on ethnic disparities (Public Health England (PHE) 2020a; 2020b). Both of these reports show examples of the presence/absence of mixed race at the institutional level. As with the Sewell Report, mixed race is nominally acknowledged and sparsely explored when trying to understand the different ways that disparities are experienced among minoritised ethnic groups. In the case of PHE, however, mixed race is most commonly overlooked in favour of generalisations maintained at the "non-White" pan-ethnicities level.

Disparities in the Risk and Outcomes of COVID-19 (Public Health England (PHE) 2020b) was the first of the two PHE reports. As mentioned, the report highlighted various identified disparities, including age, sex and gender, geography, migration status, occupation, and ethnicity. When speaking specifically about ethnic disparities, the analyses used a combination of disaggregated data and reporting at the ethnic group level, broader aggregation at the ethnicity group level, and the use of BAME to refer to "non-White" ethnicities collectively. When analysing the Mixed or Multiple ethnicity groups, most reporting was conducted on the ethnicity group level, using unrecommended terms, such as "Mixed", "Mixed ethnic group", and "Mixed ethnic groups" (Public Health England (PHE) 2020b).

The follow-up report, Beyond the Data: Understanding the Impact of COVID-19 on BAME Communities (Public Health England (PHE) 2020a), turns its focus to examine how ethnicity specifically is impacting COVID-19 infection, hospitalisation, and mortality rates in the UK. Similar to the PHE's first report, analyses use a combination of disaggregated ethnic groups, ethnicity level grouping, and BAME to describe "non-White" ethnicities. Again, Mixed or Multiple ethnic groups are mentioned minimally and at the ethnicity group level, using the unrecommended terms of "Mixed", "mixed", and "mixed ethnicity" (Public Health England (PHE) 2020a).

The BAME level of analyses predominates both PHE reports, with observations or conclusions generalising about the group as a whole, or at times referring to "some BAME" groups or communities (e.g., Public Health England (PHE) 2020a, pp. 35, 36, 41; Public Health England (PHE) 2020b, p. 39). Even though BAME is not an officially recognised ethnic term, PHE does not define it other than to list out what it stands for (Aspinall 2020; Public Health England (PHE) 2020a, 2020b). Previous research has critiqued the increased use of broad ethnicity labels, such as BAME and its predecessor, BME (Black and Minority Ethnic), specifically in the wake of the COVID-19 pandemic (Aspinall 2020, 2021a, 2021b; Milner and Jumbe 2020; Platt and Warwick 2020). Writing about the Department of Health specifically, Peter Aspinall notes that " $\mathrm{t}$ ] he rapid increase in the use of 'BAME' by government has nowhere been more conspicuous than in the focus by the Department of Health and agencies over recent months on the greater risks experienced by Black and Asian groups in Britain in the COVID-19 pandemic" (Aspinall 2021b, p. 6). BAME, and terms similar to it, steal recognition and power from distinctive ethnic group populations " ... catalysed by government, with the consequent erasure of distinct ethnic identities ... " (Aspinall 2021b, p. 3).

Mixed or Multiple ethnicity is not obviously present in the BAME acronym. Hidden from view and subsumed within the "Minority Ethnic" afterthought, it is difficult to discern the specificities of minoritised ethnicities obscured within the four letters. Johan Galtung developed the notion of structural violence, which is the way by which social structures (e.g., political, cultural, and economic, etc.) create detrimental barriers and disparities around health, housing, education, employment, and crime, etc. (Galtung 1969). The disparities of the pandemic are clear cases of structural violence (Bentley 2020). However, additionally, for Mixed or Multiple ethnicities, there is a further structural violence in the ways that they remain overlooked, even as reports vacillate between amalgamating all minorities groups and focusing on aspects of other select ethnic groups.

Since the turn of the twenty-first century, race discourses in the UK have increased their use of BAME and similar labels of fictive unity, such as Afro-Caribbean, Muslims, Asians, and Europeans (Aspinall 2021b). In essence, there has been slippage into non-granular 
broad- and pan-ethnic categories, despite official guidance not to do so. Evidence of this can be seen both in the Sewell Report discussed above and in the PHE reports. This slippage has meant that for Mixed or Multiple ethnic groups, it is unclear whether and where they fit. There are no commonly used broad aggregation labels that explicitly mention Mixed or Multiple ethnicities. It is understandable that the larger ethnic groups in the UK are more prominent in race discourses. However, this should not mean that mixed race is mostly overlooked, precisely because the disparities are different among all of the recognised ethnic groups. Lucinda Platt and Ross Warwick argue that, "[a]nalysis of ethnic disproportionalities in health outcomes that aggregates groups together masks much of the story with regards to ethnic inequalities, and limits the scope for understanding why they have come about. [... ] Accounting for these factors is necessary to understand the true scale of disproportionalities as a starting point for thinking about policy responses" (2020, p. 2). Not only does concealing diversity hinder what we are able to observe, but it also has potential implications for the ways we can respond to disparities. Examining all of these differences helps to understand and address the larger effects of racisms.

In this way, mixed race appears to create a conundrum for race discourses in a system that relies on a logic of discreteness that separates humans into different racialised categories. Within this system, it is straightforward to contrast the Asian, Black, and any Other ethnicity groups against White ethnicity groups. The PHE reports were able to begin exploring clear trends among these groups by doing just that. However, a majority of the Mixed or Multiple ethnicities in the UK include both White ethnicities and "non-White" ethnicities, which appears to complicate how institutions conceptualise them. Instead of acknowledging that, Mixed or Multiple ethnic groups are briefly mentioned and then largely overlooked. As they are constructed as ethnic minorities, they are technically part of the BAME acronym, so they are quietly subsumed into it and their specific heterogeneity is concealed. For Mixed or Multiple ethnic groups in the UK, this potential heterogeneity includes diverse generational migration status, geography, experiences of racism, cultural affinities, language, religion, and age profile. About structural violence, Galtung writes, "[s]tructural violence is silent, it does not show-it is essentially static, it is the tranquil waters" (Galtung 1969, p. 173, emphasis in original). The structural violence of marginalising mixed race in the pandemic is an additional structural violence of oversight that is barely noticed. Subsumption into the BAME category leads to only a fragmented and partial picture of Mixed or Multiple ethnicity—when it is even acknowledged.

At the institutional level, mixed race is present in the PHE reports as part of the BAME groups that have been disproportionately affected by COVID-19. Additional research has found that there is specific evidence that Mixed or Multiple ethnic groups experience COVID-19 and other health disparities, but understanding is limited due to preferred focus on biological and genetic reasons rather than social, political, and economic stratifications. This focus reifies notions of cultural essentialism and misdirects responsibility onto the victims of structural violence (Meer et al. 2020). Mixed race is absent as a result of the structural violence of oversight through the fictive unity of BAME. At the institutional level, presence/absence is maintained because there is increasing use of the BAME label as a description for all minoritised ethnic groups, but in operationalisation, Mixed or Multiple ethnic groups are overlooked within the acronym. The concealed heterogeneity of all groups in the BAME label is a form of structural violence, and for Mixed or Multiple ethnic groups, the continued marginalisation of mixed race as a result of this subsumption is an additional structural violence.

\subsection{Case Three: Civil Society: Presence/Absence as Invisibility}

The story of BAME begins in the 1980s. Prior, "Black" was used as a political term to mean "non-White", and referred to both Black and Asian ethnicities. BME gained popularity from the 1980s, when "Minority Ethnic" was added to "Black" to account for increasing ethnic diversity in the UK. In the 1990s, "Asian" was added to reflect South Asians as the largest ethnic minority group. BAME has been used at institutional and state 
levels, as well as within civil society and the VCS as an inclusive term that would apply to all ethnic minorities (Aspinall 2021a; Saeed et al. 2019).

Especially since the COVID-19 pandemic and the resurgence of Black Lives Matter after the police murder of George Floyd, minoritised ethnic groups have been speaking out against the use of BAME (Bunglawala 2019; Inc Arts UK 2020). Arguments against BAME have centred around the dissatisfaction of being "lumped together" under one moniker. In most cases, individuals identify into the disaggregated categories officially recognised by the UK government that most closely align with their own senses of personal identity. With this information, external forces-in this case, institutions and the state-have created and applied an aggregated category name to diverse people groups without their input or permission.

There have been numerous recent campaigns and resistance against BAME. At the time of writing, at least five petitions have been submitted to the UK Parliament to request a debate to abolish the use of BAME to describe minoritised ethnicities. They have all been rejected because the government claims that it does not use BAME or BME, despite that not being a uniform policy for the government as a whole (Aspinall 2021b). Inc Arts $\mathrm{UK}$, an organisation that supports diversity and inclusion in the arts, convened a series of \#BAMEOver events that sought to gain consensus on how minoritised ethnic groups preferred to be addressed. Since the aforementioned events of 2020, civil society and VCS organisations have come together to discuss racisms, and included on the agenda is how BAME is embedded into problems of race and racisms in the UK. This trend has been picked up by academics and the media, and reflects a significant shift in current racial discourse (Aspinall 2021a, 2021b).

Mixed or Multiple ethnic groups are rarely explicitly mentioned within BAME discussions and are rendered essentially invisible. One notable exception is explicit consideration in the \#BAMEOver statement, which criticises the use of ethnicity group aggregation by stating, "[w]e're never just 'mixed"” (Inc Arts UK 2020, p. 1). In the virtual meeting that I attended on the topic of BAME, Black and Asian ethnicities were brought up specifically around the need for disaggregation. When I raised the question of where Mixed or Multiple ethnic groups fit, the response was, "Yeah, I don't know ... ." Another person responded, "It's a tough one ...." This was followed by silence until the topic was changed. At another time during the same meeting, attendees suggested preferred alternatives to BAME. One common alternative was to use a different label, for example "global majority", "ethnic minority", "racial minority", or "minoritised groups." The other common alternative was to name ethnic groups more specifically than BAME, for example, "African diaspora", "South Asian heritage", "East Asian Caribbean", or "Latin American heritage." No examples of alternatives for mixed race were offered during the meeting, or how mixed race would be named specifically, e.g., as Mixed or Multiple ethnicity, Mixed or Multiple Ethnicity X and Ethnicity Y (and Ethnicity Z, etc.), added as part of all represented ethnic groups, or some other alternative.

Part of the tension for Mixed or Multiple ethnicities within the BAME debates may be the White/"non-White" dichotomy at play (Ali 2020). Within White supremacy, the White/"non-White" dichotomy represents normative, unnamed, and privileged Whiteness in contrast with non-normative, othered, and marginalised "non-Whiteness" (Gabriel 2020; Gunaratnam 2003). Despite its heterogeneity, BAME is assumed, erroneously, to be homogeneously "non-White." BAME represents an obvious fiction of unity, whereby the heterogeneity and specificities of the various groups are hidden under the broad generalisation that they are not part of the White majority ethnic group (Ali 2020; Werbner 1991). As discussed in the previous case study, although a sizeable proportion of the Mixed or Multiple ethnicity group does have White ethnicity, this is negated when subsumed into BAME. As is the case at the institutional level, Mixed or Multiple ethnic groups are further concealed within BAME as they are doubly aggregated; first under the broad UK ethnicity groups and second as part of the BAME aggregation. 
As observed in the PHE reports, BAME is certainly used at times to mean "non-White." However, the "Minority Ethnic" portion of the acronym leaves the term open to include White minorities in the UK. Mac an Ghaill (2000) argues that the implicit colour paradigm in the UK over-racialises "non-White" groups and rejects the possibility of White ethnicities as racialised minorities. This leaves White ethnic minorities "deracialised" and their specific experiences with racism in the UK denied. The same mechanism may explain how the White ethnicities within some Mixed or Multiple ethnic groups are reconciled away. When referring to Mixed or Multiple ethnic groups in the case studies above, the "non-White" background(s) are explicitly or implicitly focused upon as the reasons for experiencing racisms. In contrast, the possibility for White backgrounds to effect racisms has gone unmentioned, whether that be the influence of White minoritised ethnic background(s), or the ways that White majority ethnicity interacts with minoritised ethnicities in experiences of racisms. The White/"non-White" dichotomy further conceals the complex racialisation processes for Mixed or Multiple ethnic groups through deracialising White ethnicities and over-racialising "non-White" ethnicities to create a fictional representation of their experiences.

The presence/absence of mixed race within the BAME debates of civil society and the VCS is one of invisibility. There are many voices for minoritised ethnic groups advocating against the continued use of BAME, however Mixed or Multiple ethic groups are not prominent among them. The outcome from the various campaigns is that minoritised ethnic groups want to identify themselves into their preferred ethnic categories, rather than be designated into categories outside of their choosing. They want to resist the confines of White supremacy that decentre and marginalise their position in contrast to Whiteness. Their arguments align with wider debates, contesting structure by advocating agency (Aspinall 2021b). For Mixed or Multiple ethnic groups, within a nomenclature of disaggregation on their terms, their previously concealed diversity and the tensions and complexities of holding simultaneous multiple ethnic identities can be made visible.

\section{Conclusions}

A broad narrative appears through the examination of the above case studies from the state, institutional, and civil society/VCS levels. The state presents an argument against the existence of institutional, structural, and systemic racisms. Institutions highlight clear examples of these racisms by illuminating racial health disparities of "non-White" BAME groups. Civil society and the VCS resist the imposition of BAME as an additional form of racism, and advocate to be seen as separate and distinct ethnic communities for the purposes of better exposing racisms.

The case studies also expose the ways that mixed race is simultaneously present and absent in UK racial discourses. As one of the fastest growing ethnicities throughout the UK, Mixed or Multiple ethnic groups are a significant influence in the ever-shifting racialised landscape. Despite this, talk of race and ethnicity has shifted over time from a focus primarily on Black and Asian groups to the fictive unity of BAME. While in name, this acronym allows for the potential inclusion of increased racialised ethnicities, in practice those comprising the "Minority Ethnic" part of the term remain marginalised in their amalgamation. This is especially true for Mixed or Multiple ethnicities, where their particular ethnicities, experiences of racisms, and connections to Whiteness disrupt the less-nuanced White/"non-White" dichotomy.

The presence/absence of mixed race is the direct result of the implementation of White supremacy. The structural violence of White supremacy creates the simplified caricatures of racialised experiences contained in the Sewell Report, and is further perpetuated as Mixed or Multiple ethnicities are used to support the denials of racisms. Continued structural violence at the institutional level acknowledges racial disparities, but relies on the generalities of fictive unities, which mask the particular dynamics at play for the specific disparities Mixed or Multiple ethnicities face. Structural violence also invisiblises Mixed or Multiple ethnic groups through both the creation and contestation of fictive unities, 
reinforcing the power dynamics embedded within a White/"non-White" dichotomy to stratify via racialisation. The tools maintaining socio-political power for White supremacy set up the perpetual struggle for any remaining agency among those oppressed by racisms. These case studies show that within these struggles, Mixed or Multiple ethnic groups are nominally present and broadly included but are simultaneously subsumed by the replicated tools of race, racialisation, and racisms.

As a technology of power, race, racialisation, and racisms continue to have wide implications for understanding mixed race and race more broadly. Fiction of unity and structural violence create countless areas for presence/absence to occur for all racialised groups through their nature of aggregation, subsumption, and invisibilisation. The presence/absence at civil society and VCS, institutional, and state levels of society continues to affect mixed race people-and all racialised people-living in/under White supremacy.

Funding: This research received no external funding.

Data Availability Statement: Data sharing is not applicable.

Acknowledgments: The author wishes to thank the anonymous community group for their participation in this study. The author is also grateful to the editors of Social Sciences, the editors of this special issue, David Brunsma and Jennifer Sims, and to the anonymous reviewers for their engaging comments on this manuscript.

Conflicts of Interest: The author declares no conflict of interest.

\section{Notes}

1 "Non-White" is a contested term. Some have found it problematic because it refers to racially minoritised groups in the negative, against the 'norm' of Whiteness. My use of it in this article is one of pragmatics: although it is not an ideal term, it highlights the imagined associated binaries of us/them, native/foreign, and superior/inferior, etc., when invoked within the system of White supremacy.

2 Imperial nationalism, as discussed by Magne Flemmen and Mike Savege, specifially referes to racist discourses and beliefs around the imperial greatness or supremacy of the UK, in contrast to nationalist populism, which is based more on personal feelings or attachments to the nation, e.g., English, Scottish, Welsh, and Irish identies (Flemmen and Savage 2017).

3 "Slippage" refers to the concept as developed by Jungmiwha Suk Bullock, which refers to the phenomenon of biological essentialism covertly underpinning social constructionist explanations of race (Bullock 2010).

$4 \quad$ Scotland and Northern Ireland use slightly different ethnic groups and configurations on their census forms. Wales separates English, Welsh, Scottish, Northern Irish, and British to individual categories and transposes Welsh and English on their list (GOV.UK 2021a).

5 "British" can be considered a national identity (as part of the nation of Great Britain or the United Kingdom) and a geopolitical region (consisting of the countries of England, Scotland, and Wales) (GOV.UK 2021b).

6 Coined by Philomena Essed and David Theo Goldberg, race-critical approaches focus on the ways that race works vis-à-vis the construction and categorisation of people groups, human rights, social opportunities, and discrimination at every level of society. “... [C]ritical theory necessarily requires a focus, among others, on race; and racial theory cannot help but be, in a normative sense, critical. [ ... ] We do not intend this as a play of words, but as an indication of a specific theoretical disposition." (Essed and Goldberg 2002, p. 4).

7 "BAME" has increased in usage (and contestation) as a catch-all term for all minoritised racial and ethnic groups in the UK over the last two decades. Recently, however, it has undergone more widespread critique in the civil society and voluntary and community, media, academic, and other sectors. BAME will be discussed in further detail in the case studies below.

8 Benedict Anderson describes imagined communities as socially constructed communities based on geopolitical notions of national boundary and citizenship identity (Anderson 1991).

\section{References}

Ahmed, Sara. 2007. A Phenomenology of Whiteness. Feminist Theory 8: 149-68. [CrossRef]

Aldridge, Robert W., Dan Lewer, Srinivasa Vittal Katikireddi, Rohini Mathur, Neha Pathak, Rachel Burns, Ellen B. Fragaszy, Anne M. Johnson, Delan Devakumar, Ibrahim Abubakar, and et al. 2020. Black, Asian and Minority Ethnic Groups in England are at increased Risk of Death from COVID-19: Indirect Standardisation of NHS Mortality Data. Wellcome Open Research 5: 88. [CrossRef] [PubMed]

Ali, Sawen. 2020. 'BAME' Is an Outdated Term, Struggling to Define the Experiences of Those Who Do Not Identify as White. Varsity. June 5. Available online: https:/ / www.varsity.co.uk/opinion/19351 (accessed on 26 September 2021). 
Anderson, Benedict. 1991. Imagined Communities: Reflections on the Origin and Spread of Nationalism. London: Verso.

Aspinall, Peter J. 2020. Ethnic/Racial Terminology as a Form of Representation: A Critical Review of the Lexicon of Collective and Specific Terms in Use in Britain. Genealogy 4: 87. [CrossRef]

Aspinall, Peter J. 2021a. BAME (Black, Asian and Minority Ethnic): The 'New Normal' in Collective Terminology. Journal of Epidemiology and Community Health 75: 107. [CrossRef] [PubMed]

Aspinall, Peter J. 2021b. 'Black African' Identification and the COVID-19 Pandemic in Britain: A Site for Sociological, Ethical and Policy Debate. Sociology of Health and Illness 43: 1789-800. [CrossRef] [PubMed]

Bentley, Gillian R. 2020. Don't Blame the BAME: Ethnic and Structural Inequalities in Susceptibilities to COVID-19. American Journal of Human Biology 32: e23478. [CrossRef] [PubMed]

Bhambra, Gurminder K. 2017. Brexit, Trump, and 'Methodological Whiteness': On the Misrecognition of Race and Class. The British Journal of Sociology 68: S214-32. [CrossRef] [PubMed]

Bullock, Jungmiwha Suk. 2010. Multiracial Politics or the Politics of Being Multiracial?: Racial Theory, Civic Engagement, and Socio-Political Participation in a Contemporary Society. Ph.D. dissertation, University of Southern California, Los Angeles, CA, USA.

Bunglawala, Zamila. 2019. Please, Don't Call Me BAME or BME!" Civil Service. Available online: https://civilservice.blog.gov.uk/2019 /07/08/ please-dont-call-me-bame-or-bme (accessed on 26 September 2021).

Byrne, Bridget, Claire Alexander, Omar Khan, James Nazroo, and William Shankley. 2020. Ethnicity, Race and Inequality in the UK: State of the Nation. Bristol: Bristol University Press.

Byrne, David. 2005. Class, Culture and Identity: A Reflection on Absences Against Presences. Sociology 39: 807-16. [CrossRef]

Christian, Mark. 2002. An African-Centered Perspective on White Supremacy. Journal of Black Studies 33: 179-98. [CrossRef]

Commission on Race and Ethnic Disparities (CERD). 2021. Commission on Race and Ethnic Disparities: The Report; London: UK Government. Available online: https: / / www.gov.uk/government/publications/the-report-of-the-commission-on-race-andethnic-disparities (accessed on 12 April 2021).

Donoghue, Matthew, and Mikko Kuisma. 2021. Taking Back Control of the Welfare State: Brexit, Rational-Imaginaries and Welfare Chauvinism. West European Politics 45: 177-99. [CrossRef]

Dyer, Richard. 2017. White: Twentieth Anniversary Edition. London: Routledge.

Essed, Philomena. 1991. Understanding Everyday Racism. London: SAGE Publications.

Essed, Philomena, and David Theo Goldberg, eds. 2002. Race Critical Theories: Text and Context. Malden: Blackwell Publishers Inc.

Fields, Karen Elise, and Barbara J. Fields. 2014. Racecraft: The Soul of Inequality in American Life. London: Verso.

Flemmen, Magne, and Mike Savage. 2017. The Politics of Nationalism and White Racism in the UK. The British Journal of Sociology 68: S233-S264. [CrossRef] [PubMed]

Gabriel, Deborah. 2020. Racial Categorisation and Terminology. Black British Academics. August 3. Available online: https:// blackbritishacademics.co.uk/about/racial-categorisation-and-terminology (accessed on 30 September 2021).

Galtung, Johan. 1969. Violence, Peace, and Peace Research. Journal of Peace Research 6: 167-91. [CrossRef]

Glasgow, Joshua. 2009. A Theory of Race. New York City: Routledge.

Goldberg, David Theo. 2006. Racial Europeanization. Ethnic and Racial Studies 29: 331-64. [CrossRef]

GOV.UK. 2021a. List of Ethnic Groups. Available online: https://www.ethnicity-facts-figures.service.gov.uk/style-guide/ethnicgroups (accessed on 23 September 2021).

GOV.UK. 2021b. Toponymic Guidelines for Map and Other Editors, United Kingdom of Great Britain and Northern Ireland. Available online: https://www.gov.uk/government/publications/toponymic-guidelines/toponymic-guidelines-for-map-and-othereditors-united-kingdom-of-great-britain-and-northern-ireland--2\#geopolitical-terminology (accessed on 24 September 2021).

Gunaratnam, Yasmin. 2003. Researching Race and Ethnicity: Methods, Knowledge and Power. London: Sage.

Hacking, Ian. 1999. The Social Construction of What? Cambridge: Harvard University Press.

Hesse, Barnor. 2013. Raceocracy: How the Racial Exception Proves the Racial Rule. Irving K. Barber Learning Centre, University of British Columbia. Available online: https:/ / dx.doi.org/10.14288/1.0076724 (accessed on 26 September 2021).

Inc Arts UK. 2020. A Statement for the UK. \#BAMEOver. Available online: https://incarts.uk/\%23bameover-the-statement (accessed on 24 October 2020).

Iqbal, Nosheen. 2021. Downing Street Rewrote 'Independent' Report on Race, Experts Claim. The Guardian. April 11. Available online: https:/ /www.theguardian.com/uk-news/2021/apr/11/downing-street-rewrote-independent-report-on-race-expertsclaim (accessed on 12 April 2021).

Lentin, Alana. 2008. Europe and the Silence about Race. European Journal of Social Theory 11: 487-503. [CrossRef]

Lentin, Alana. 2020. Why Race Still Matters. Cambridge: Polity Press.

Mac an Ghaill, Máirtín. 2000. The Irish in Britain: The Invisibility of Ethnic and Anti-Irish Racism. Journal of Ethnic and Migration Studies 26: 137-47. [CrossRef]

Macfarlane, Karen S. M. 2021. How Do UK Archivists Perceive ‘White Supremacy' in the UK Archives Sector? Archives and Records. [CrossRef]

Meer, Nasar, Kevari Quershi, Ben Kasstan, and Sarah Hill. 2020. The Social Determinants of COVID 19 and BAME Disproportionality. Discover Society. Available online: https: / archive.discoversociety.org/2020/04/30/the-social-determinants-of-covid-19-andbame-disproportionality (accessed on 25 September 2021). 
Milner, Adrienne, and Sandra Jumbe. 2020. Using the Right Words to Address Racial Disparities in COVID-19. The Lancet Public Health 5: e419-20. [CrossRef]

Njaka, Chinelo L. 2021. Race and Racism(s): Current Debates in Global and UK Theorisation and Empiricism. Sociology 55: 641-45. [CrossRef]

Office of the United Nations High Commissioner for Human Rights (OHCHR) and United Nations Educational, Scientific, and Cultural Organization (UNESCO). 2003. Dimensions of Racism. Geneva: United Nations.

Omi, Michael, and Howard Winant. 2015. Racial Formation in the United States, 3rd ed. New York City: Routledge.

Platt, Lucinda, and Ross Warwick. 2020. Are Some Ethnic Groups More Vulnerable to COVID-19 than Others? Inequality: The IFS Deaton Review. Institute for Fiscal Studies. Available online: https://www.ifs.org.uk/inequality/wp-content/uploads/2020/0 4/Are-some-ethnic-groups-more-vulnerable-to-COVID-19-than-others-V2-IFS-Briefing-Note.pdf (accessed on 26 October 2020).

Proto, Eugenio, and Climent Quintana-Domeque. 2021. COVID-19 and Mental Health Deterioration Among BAME Groups in the UK. PLoS ONE 16: e0244419. [CrossRef] [PubMed]

Public Health England (PHE). 2020a. Beyond the Data: Understanding the Impact of COVID-19 on BAME Communities. London: Public Health England.

Public Health England (PHE). 2020b. Disparities in the Risk and Outcomes of COVID-19. London: Public Health England.

Saeed, Amani, Elliott Rae, Rob Neil, Vivienne Connell-Hall, and Frank Munro. 2019. To BAME or Not to BAME: The Problem with Racial Terminology in the Civil Service. Civil Service World. October 4. Available online: https:/ /www.civilserviceworld.com/ news / article/to-bame-or-not-to-bame-the-problem-with-racial-terminology-in-the-civil-service (accessed on 26 September 2021).

Sims, Jennifer Patrice, and Chinelo L. Njaka. 2020. Mixed-Race in the US and UK: Comparing the Past, Present, and Future. Bingley: Emerald Publishing, Limited.

Treweek, Shaun, Nita G. Forouhi, and K. M. Venkat Narayan. 2020. COVID-19 and Ethnicity: Who Will Research Results Apply To? The Lancet 395: 1955-57. [CrossRef]

Werbner, Pnina. 1991. The Fiction of Unity in Ethnic Politics: Aspects of Representation and the State among British Pakistanis. In Black and Ethnic Leaderships. The Cultural Dimensions of Political Action. Edited by Pnina Werbner and Muhammad Anwar. London: Routledge. 